\title{
In Defense of Bad Infinity \\ A Fichtean Response to Hegel's Differenzschrift
}

\author{
Wayne M. Martin \\ Alas, poor Yorick! I knew him, Horatio: a fellow of infinite jest ... \\ Shakespeare
}

One must imagine Sisyphus happy.

Camus

Hegel's very first acknowledged publication was, among other things, an attack on Fichte. ${ }^{1}$ In 1801, Hegel was still laboring in almost complete obscurity, while Fichte was an international sensation, though already somewhat past the peak of his meteoric career. In the 1801 Differenzschrift, Hegel cut his teeth by criticizing Fichte's already widely-criticized Wissenschaftslehre, and by demonstrating that Schelling's philosophical system was not simply to be equated with it. Fichte himself never bothered to respond to Hegel's criticisms; indeed he never publicly acknowledged their existence. This was not because he was unconcerned with criticisms of his views; quite the contrary. But at the time he had bigger fish to fry. He responded to Jacobi's criticisms, and to Schelling's; he replied in great detail to critical questions raised by Reinhold, and with vituperative intensity to objections raised by skeptics and purportedly loyal Kantians. But Hegel's Differenzschrift was left without a Fichtean rebuttal. This is a pity, both because of the missed opportunity to illuminate by controversy central issues at stake in the post-Kantian period, but also because it made it easier for Hegel simply to reiterate his youthful criticism as if it were the last word. And reiterate it he did: in one form or another Hegel's early criticisms of Fichte reappear at every subsequent stage of his career: in the Phenomenology, in the Science of Logic, in the Encyclopaedia, as the final chapter in Hegel's History of Philosophy, and in countless other minor works and documents from the Nachlass and correspondence.

\footnotetext{
${ }^{1}$ G.W.F. Hegel, Differenz des Fichte'schen und Schelling'schen Systems der Philosophie (Jena: 1801); citations are given with the abbreviation DZ and refer to the translation by Cerf and Harris: The Difference Between the Fichte's and Schelling's Systems of Philosophy (Albany New York: SUNY Press, 1977). Concerning Hegel's earlier anonymous publications see the Cerf and Harris edition, p. 66n1.
} 
The purpose of this essay is to give Fichte the chance to answer back. I shall not attempt to address every element of Hegel's critique, and indeed I shall here bypass some of the issues that others have made central to the Fichte-Hegel divergence. (In particular I shall have nothing directly to say here about the charge of subjective idealism, which has been much discussed in this connection.) I focus instead on what Hegel himself clearly marks as the major thrust of his critique: the allegation that Fichte "betrays the principle of subject-object identity." I propose to treat this objection in the context of the Hegelian notion of Bad Infinity (schlechte Unendlichkeit). Though the term "bad infinity" does not in fact occur in the Differenzschrift, I shall argue that this influential Hegelian concept is indeed at work there, and moreover that the central force of Hegel's objection to Fichte revolves around the allegation that Fichte is, as I shall put it, a philosopher of the bad infinite.

My discussion proceeds in two main parts. The first two sections of the paper are mainly expository and historical. In $\S 1$ I introduce the Hegelian account of Bad Infinity, exhibiting the main elements of the logic of this concept by drawing on its canonical treatment in the later editions of The Science of Logic. In $\$ 2$ I turn to its critical role in Hegel's Fichte-Critique. I show that, despite the absence of this term from Hegel's Differenzschrift, the concept of Bad Infinity is indeed first formulated in that work and that Hegel's anti-Fichtean argument effectively revolves around it. The second part of the paper then engages the controversy. In $\S 3$ I consider how Fichte could have responded to the Hegelian charge, and how in turn a Hegelian might press his objection in light of the Fichtean reply I propose. I shall argue that the disputed issues quickly come to settle on an cluster of problems about what I shall call "Bad Infinite Ideals" - ideals which purportedly retain their authority despite remaining in principle beyond the reach of finite human endeavor - and I consider the divergence between a Fichtean and Hegelian approach to such ideals. In the final section I argue that neither side emerges with a clear victory in this dispute. In this sense the present paper is inconclusive, but my hope is that enacting the controversy may itself prove illuminating both historically and philosophically. I conclude with a few provisional remarks about how to proceed in the light of such a stalemate.

\section{$\S 1$ The Logic of Bad Infinity}

The term Bad Infinity first appears in Hegel's published writings in the Science of Logic, where it plays a central role. I begin with a brief survey of Hegel's discussion there, not with an eye to plumbing the considerable complexity of his treatment of infinity, but rather with the aim of providing a preliminary plotting of the distinctive shape of this influential Hegelian concept. In the Science of Logic, Hegel's discussion of infinity opens with a distinction:

The infinite, however, is held to be absolute without qualification for it is determined expressly as the negation of the absolute. ... But even so, the infinite is not yet really free from limitation and finitude; the main point is to distinguish the genuine 
Notion of infinity from the bad infinite, the infinity of reason from the infinity of the understanding. (SL 1372)

Here already we can see Hegel's introduction of the contrast that will concern us. The infinite admits of these two interpretations, dubbed by Hegel as "echt" and "schlecht" respectively; an adequate probing of the logic of infinitude must learn to distinguish quite sharply between the two.

Straightaway translation issues impose themselves on our discussion. The term "schlecht" is the standard German equivalent to the English word "bad," and I have thus far simply followed this common equivalence. Many of Hegel's recent translators, however, have rendered "schlecht" rather as "spurious," presumably because it is here introduced in contrast with "echt" -- the genuine or true infinity. As we shall soon find, quite a lot comes to ride on the choice between these two translations. To think and speak of schlecht Unendlichkeit as bad infinity is to think of it as a variety of infinity, albeit a variety that is bad. The sense in which infinity could be bad remains to be specified, but already with such an approach one has in certain fundamental respects prejudged the issues. A bad dog is a dog, a bad painting is a painting, so bad infinity would itself presumably be a form of infinitude. On the other hand, to speak and think instead of spurious infinity is to prejudge the issues in a different direction. For spurious infinity is presumably not really infinite; "spurious" suggests a fake, a forgery or a counterfeit of some sort. For present purposes I shall simply follow the dictionary in rendering "schlecht" as "bad." But I recognize that this is not an innocent choice, and I shall propose in due course some neutral terminology in which we might construct the issues.

Hegel provides a first characterization of the bad infinite in the context of his discussion of the so-called "qualitative infinite."

The infinite as thus posited over against the finite, in a relation wherein they are as qualitatively distinct others, is to be called the bad infinite, the infinite of the understanding, for which it has the value of the highest, the absolute truth. (SL 139) This passage has the look of a definition, but it is not, for as we shall see presently there are important forms of bad infinitude that are quantitative rather than qualitative. But it nonetheless provides a first glimpse of the kind of structure that Hegel is concerned with. The very term "in-finitude" $-U n$ endlichkeit - suggests that the concept is to be constructed as the negation of the finite. The infinite would be, on this approach, defined by its opposition to finitude, and in this sense "posited over against" it. For Hegel the exemplar of this conception is the understanding of divine infinitude inscribed in orthodox Christianity. God's infinitude, on this conception, is strictly distinguished from the finitude of God's creation, and 'posited over against it.'

But perhaps the most useful characterizations of the bad infinite come in the context of Hegel's account of the logic of mathematics. ${ }^{3}$ For Hegel there provides an exemplar - and an image -

\footnotetext{
${ }^{2}$ G.W.F. Hegel, Wissenchaft der Logik; citations are given with the abbreviation SL and refer to the English translation by A.V. Miller: Hegel's Science of Logic (New York, Humanities Press, 1969).

${ }^{3}$ For a useful overview of Hegel's philosophy of mathematics, see Terry Pinkard, "Hegel's Philosophy of Mathematics"; Philosophy and Phenomenological Research, 41:4 (1981), pp. 452-464.
} 
of bad infinitude that will shape much of his discussion. In this context Hegel's central example of Bad Infinity is not God but rather the number series. The number series is probably the most familiar and canonical example of infinitude in modern discussions; indeed we are now inclined to think of infinity as a numerical concept. ${ }^{4}$ For Hegel such an equation is mistaken, as we will see, but nonetheless much of the conceptual structure of bad infinity comes into view when we think about the infinitude of the number line. So what do we mean when we say that the number series is infinite? In modern mathematical discussions this issue has been intensely disputed, but we can at least formulate one answer by appeal to the familiar distinction between the intensive and extensive infinitude of the series of real numbers. The real number series is extensively infinite in the sense that it has no end, no final number beyond which there are no more. And the real number series is intensively infinite insofar as it is dense with numbers: between any two one finds a third. Hence if we consider two real numbers $m$ and $n$, then by the principle of extensive infinitude, $m+1$ is also a real number; by the principle of intensive infinitude $1 / 2(m+n)$ is also a real number. In both cases we tend to associate of the infinitude of numbers with the idea that, as we say, "they go on and on and on ...", "there is no end to them."

In this idea of "going on and on and on" into an infinitely receding distance, we find one of the hallmarks of the bad infinite as Hegel understands it. To say that some thing is in-finite, unendlich, seems to mean that there is no getting to the end of it. One can go indefinitely far along the series - as long as one has the will and patience to go - yet one will never get to the end of the line. In contemporary thought we tend to think of this particular structure as more-or-less definitive of the notion of infinitude. When Camus writes about infinitude, he takes the labors of Sisyphus as his exemplar: struggling to push his rock up a hill again and again and again without end. ${ }^{5}$ When Bernard Williams writes about immortality, he writes about it as a form of existence that goes on and on and on and on through time, never coming to an end. ${ }^{6}$ When we wonder whether space is finite or infinite, we wonder in effect whether one could go on and on and on without either coming to the end of it or arriving back at where one started. For Hegel all this marks the force of Bad Infinity in structuring modern thinking about the infinite.

So if we understand Bad Infinity along these lines, then what exactly is meant to be bad about it? Indeed what can it possibly mean to call infinity bad at all? It is worth distinguishing three different elements in Hegel's critique. First, as a schema for infinitude, bad infinity is at best

\footnotetext{
${ }^{4}$ Note however that this is not yet to say that infinity is itself a number. The question of whether infinity is indeed to be treated as a number has been hotly disputed. For the canonical discussion see Georg Cantor Contributions to the Founding of the Theory of Transfinite Numbers, translated by Philip Jourdain (New York: Dover, 1915). For a helpful discussion see A.W. Moore, The Infinite (London and New York: Routledge, 1990).

${ }^{5}$ A. Camus, "Le mythe de Sisyphe” (1942); translated by Justin O’Brien in The Myth Of Sisyphus, And Other Essays (New York: Knopf, 1955).

${ }^{6}$ B.A.O. Williams, "The Makropulos Case: Reflections on the Tedium of Immortality"; in Problems of the Self (Cambridge: Cambridge UP, 1973).
} 
incomplete and one-sided. Even within mathematics we can find examples of infinite structures that would direct our thinking about infinitude in quite different directions. Hegel himself cites the example of a circle, which is in-finite in having no ends (SL 149). The mathematical symbol for infinitude, which dates back at least to the $17^{\text {th }}$ century, provides another emblem: a figure-eight lying on its side, a closed but in-finite circuit. For our purposes here I propose to appeal to the somewhat anachronistic example of the Möbius Strip. A Möbius strip is twisted band, easily constructed from a strip of paper by closing it into a circular form after introducing a single twist. Why should we think of it as infinite? Well, like Hegel's circle it has no ends. But it is also mathematically distinctive in being a closed figure that has no inside and no outside. Hence in several respects it seems fitting to describe it as 'end-less.' The crucial thing, however, is that it does not go on and on and on forever. It is a totality; the whole thing is here present on my writing table. So we need not think of in-finitude (the absence of ends) in terms of the schema of trailing off endlessly into the distance. ${ }^{7}$

A second strand in Hegel's protest against the hegemony of the Bad Infinite concerns not so much the concept itself as the use (or rather: abuse) to which it is put. In one of the most scathing and entertaining additions [Zusätze] in the Science of Logic, Hegel mocks what he calls the "high repute" of Bad Infinity, particularly in connection with what he calls "the infinite progress" (SL 150-154). In short, his allegation is that in broad range of modern thought (whether in aesthetics, in ethics, in theology, in cosmology ...) structures of bad infinity are overrated and unduly celebrated. The waves at the beach go on and on and on. But if you are inclined to suppose that the beach thereby brings you closer to the presence of God, you are in the grip of the Bad Infinite. If you think that the infinitude of space must be modeled on that of the number line then your cosmological imagination has been corrupted by Bad Infinity. (Perhaps it is a multi-dimensional analogue of a Möbius Strip, or a donut, or some other form of in-finite totality.) And if you think that the highest forms of artistic representation must provide some inkling of an unrepresentable-because-unending sublime, then both your art and your aesthetics will be as bad as your infinitude.

Quite aside from these abuses, however, Hegel also thinks that there is a logical flaw in the Bad Infinite, and it is this above all that is meant to warrant the term "schlecht." The complaint here is not just that the number series, for instance, or an orthodox Christian God are one-sided examples of infinity; the allegation is that they are bad examples of infinity. Why? Because in each case, as we might initially put the point, finitude is incompletely negated. God is thought to be infinite and so is defined in complete opposition to the forms of finitude found in the creation. But this means in effect

\footnotetext{
${ }^{7}$ Here one may find oneself tempted to assimilate these purported alternative configurations of the infinite back to the usual model. Hence for instance one may be willing to describe a circle or a Möbius strip as infinite only because one can go round and round on it without end. ("If it is really infinite then there must be an "on and on and on' structure in it.") But we need not think in this way, and to use Hegel's examples as a clue requires that we resist the temptation to render them familiar along Bad Infinite lines. It is perhaps testimony to the power that Bad Infinity holds over our thinking about the infinite that we feel the pressure to accommodate alternatives to its schema in this way.
} 
that God encounters his limit in finitude; yet to be limited is it be finite. The number series is used to illustrate the infinite, even to exemplify it, yet no matter how far one goes along it one is always left with a further finite quantity. One thus never actually finds the infinite along such a path. In neither case, in short, do our representations of infinitude fully satisfy the logic of the concept. Hegel:

the quantum is maintained in perpetual opposition to its beyond. No matter how much the quantum is increased, it shrinks to insignificance; ... the increase in quantum brings it no nearer to the infinite. ... This infinity which is perpetually determined as the beyond of the finite is to be described as the bad qualitative infinite. (SL 228; emphasis added)

It is for just this reason, of course, that translators have come to render Hegel's "schlecht" as "spurious." For the claim here seems to be that these familiar exemplars of infinitude are themselves not genuine infinities; they purport to be but are not infinite. In short they are counterfeit, spurious infinitudes.

At this point it would be natural to follow the trajectory of this Hegelian thought and consider what, if anything, would then provide an example of good or true (echt) infinitude. ${ }^{8}$ And indeed to a considerable extent this is the question from which much of the structure of Hegelian philosophy can be seen to flow. But I shall not follow this lead here, since my topic is not Good Infinity but its badly behaved brother. And we have now gone far enough to recognize the main outlines of this distinctively Hegelian notion, at least as it makes its appearance in the Logic. Before going on, however, it will be worthwhile to mark, albeit only briefly, three further attributes that Hegel on occasion associates with Bad Infinitude, as they form an important part of the subsequent history of this Hegelian concept. In at least one passage Hegel associates Bad Infinitude with modernity - an association that would figure centrally in the Marxist deployment of the concept in the analysis of capitalism. ${ }^{9}$ In several places Hegel suggests that Bad Infinity is subjective, which of course links this concept to one of his famous

\footnotetext{
${ }^{8}$ For a helpful recent discussion, see Stephen Houlgate, The Opening of Hegel's Logic: From Being to Infinity (West Lafayette, Indiana: Purdue University Press, 2006), especially Chapter 22: "True Infinity".

${ }^{9}$ Marx claims that capitalism is essentially oriented toward an incompleteable infinitude, an orientation grounded in the ontology of capital itself. See for instance this remark in Grundrisse: "A specific sum of money ... can entirely suffice for a specific consumption, in which case it ceases to be money. But as a representative of general wealth, it cannot do so. As a quantitatively specific sum, a limited sum, it is only a limited representative of general wealth, or representative of a limited wealth, which goes as far, and no further than, its exchange value, and is precisely measured in it. It thus does not by any means have the capacity which according to its general concept it ought to have, namely the capacity of buying all pleasures, all commodities, the totality of the material substances of wealth ... . Fixed as wealth, as the general form of wealth, as value which counts as value, it is therefore the constant drive to go beyond its quantitative limit: an endless process." Karl Marx, Grundrisse:
} Foundations of the Critique of Political Economy; translation by Martin Nicolaus, (London: Penguin, 1973), 270. For a discussion see Christopher Arthur, "The Infinity of Capital”; Studies in Marxism V (1998); reprinted in The New Dialectic and Marx's Capital (Leiden: Brill, 2004), 137-152. 
criticisms of his idealist predecessors. And in an association that will figure importantly in the controversy with which we shall be concerned, Hegel treats the logic of Bad Infinity as intimately associated with the logic of the notion of "ought" [Soll], particularly as that notion figures in Kantian morality. Indeed it is Hegel's exploration of the logic of "ought" that first raises the theme of infinitude in the Logic at all:

In the ought the transcendence of finitude, that is, infinity, begins. The ought is that which, in the further development, exhibits itself in accordance with the said impossibility as the progress to infinity. (SL, 134)

But I set aside these further associations for now in order to focus our attention on the role of the notion of Bad Infinity in Hegel's critique of Fichte.

\section{$\S 2$ Bad Infinity in Hegel's Critique of Fichte}

So what does all this have to do with Fichte? As it turns out, I think, the answer is: "quite a lot.” In what follows I argue for three main claims. I show first that Hegel's critique of Fichte is intimately tied up with the notion of Bad Infinity, and indeed ultimately comes to be formulated in terms of this notion. Second, I show that, despite the absence of the term "Bad Infinity" from the Differenzschrift, the concept is in fact first worked out in that text and plays a crucial role there. Finally, in all this it shall emerge that, for Hegel, Fichte is the philosopher of Bad Infinity par excellence.

In order to bring all this out, it will be useful to start near the end of the Hegelian corpus and work our way back. In traversing such a path, we can begin with the text of Hegel's colossal Lectures on the History of Philosophy, which were formally published only posthumously, based mainly on transcript notes from Hegel's assiduous students. Here we must keep in mind that for Hegel, Fichte effectively marks the end of the history of philosophy, and accordingly that the critique of the Wissenschaftslehre occupies the final step in the self-serving story that culminates in the need for the Hegelian turn. Accordingly, the final few pages of Hegel's History of Philosophy are concerned with Fichte (something of a slight to Schelling, to be sure!), together with a few remarks about some of his more noteworthy or ridiculous successors and imitators.

By the time of the History lectures, Hegel's critical remarks about Fichte's project are pretty well honed, and the thrust of this criticism is there summed up efficiently:

Fichte does not attain to the idea of Reason as the perfected, real unity of subject and object, or of ego and non-ego; it is only, as with Kant, represented as the thought of a union in belief or faith, and with this Fichte likewise concludes. ... For because the ego is fixed in its opposition to the non-ego, and is only as being opposed, it becomes 
lost in that unity. The attainment of this aim is hence sent further and further back into the bad, sensuous infinitude ... . ${ }^{10}$

We can already see here that the purported flaw in Fichte's philosophical position is intimately tied up with the notion of Bad Infinity. On Hegel's pithy summary, the Bad Infinitude of Fichte's position emerges as the inescapable consequence of four elements of the Fichtean account of subjectivity (the I or Ego - "das Ich"). The first and basic point is that for Fichte, a subject is always set over against and limited by an object; the two are "fixed in opposition." always opposed in this way, it cannot attain what both Hegel and Fichte refer to as "subject-object unity" - a unity in which the division between subject and object is somehow superceded or overcome. Accordingly (this is the third point), the principle of subject-object identity can figure in the Wissenschaftslehre only as a projected goal, an object of faith or obligation or striving or longing. Finally, even though the Fichtean subject projects such a goal, the attainment of it would be incoherent and self-destructive. As Hegel puts it here: the I would lose itself in such an identity. This is simply a consequence of the initial point: if the I must be limited by a not-I, then a circumstance in which this opposition is finally overcome would also be the circumstance in which the I would cease to exist as such. In what follows I shall treat this four-point critical summary of Fichte's position as “Hegel's Bad Infinity Criticism of the Wissenschaftslehre." The Fichtean I projects as its goal a unity that it can, in principle, never attain. Accordingly, its situation can aptly be compared to that of someone trying to reach infinity by repeated applications of the rule "add one."

Before turning to assess the force of the Bad Infinity Criticism, I want to complete the historical portion of my analysis by showing that all four elements of the critical summary can be found at work in the Differenzschrift of 1801, albeit absent the specific terminology of schlechte Unendlichkeit. Given the work we have done so far, the evidence should now be quite straightforward. Rather than working through the text of the Differenzschrift in detail, I shall accordingly rest my case on three passages in which Hegel turns his critical knife. The crucial passage, and the crux of the Hegelian objection, can be found in the culminating paragraphs of Hegel's exposition of the position of the Wissenschaftslehre:

The Ego ought to nullify the objective world, it ought to have an absolute causality with respect to the non-Ego. This is found [by Fichte] to be contradictory, for it would imply suspending the non-ego .... So the connection of pure activity with an object can only be posited as a striving. ... At this point Ego=Ego has been abandoned by speculation. (DZ 132-133)

\footnotetext{
${ }^{10}$ G.W.F. Hegel Lectures on the History of Philosophy (Three Volumes); translation by Haldane and Simson (Lincoln, Nebraska: University of Nebraska Press, 1995); vol. III, page 499, emphasis added. Note that the translators in this case rendered schlechte as "false," a rendering which I have altered.
} 
In this famous passage we find the main thrust of the argument that would be repeated decades later in the History lectures. For Fichte, Hegel alleges, the principle of the Absolute I, or of an identity of subject and object is (a) obligatory (the I ought to have an absolute causality), (b) contradictory (since it would involve what Hegel would later call a "loss of self"), and (c) projected as an object of striving. In this passage the language of infinitude is lacking, but the critical conclusion is unmistakable: in so configuring his account Fichte effectively fails to realize his speculative goal, and in this sense abandons his principles.

A few paragraphs later these three elements of the critical summary are completed by explicitly introducing the language of infinite progress:

This absolute opposition of Idea and intuition, and their synthesis which is nothing but a self-destructive demand, since it postulates a union which still must not happen - all this is expressed in the infinite progress. Absolute opposition is thus shoved into the form it had at a lower standpoint which had for a long time passed current as the true suspension of opposition and the highest solution of the antinomy of Reason. Existence prolonged into eternity involves both the infinity of the Idea and intuition within itself, but in forms which make their synthesis impossible. (DZ 134)

Here we find the unmistakable anticipation of the later scornful account of "the high repute of the progress to infinity." As Hegel recognizes, the Fichtean subject is explicitly constructed as an agent which cannot attain to a goal which it also cannot give up. The Fichtean solution is to project this goal into an infinitely distant future, as a labor that can be neither avoided nor accomplished, as a defining task, and as the measure for an endeavor that can never finally measure up to its own standard. As Hegel recognizes, for Fichte this underwrites a curious version of the traditional hope for immortality: the Fichtean I inevitably projects its existence into an infinite eternity, for it is only such a capacious future that could accommodate the infinite task the Fichtean I has set itself. Depending on one's sympathies one might choose to describe such a figure as either tragic or absurd. But for Hegel all this is a mistake, a regress into a "lower," (i.e., non-speculative) understanding of the configuration of infinitude.

We can complete our backwards march through Hegel's corpus by revisiting the passage in which these shots were first fired - the Preface to the Differenzschrift, where Hegel's critical summary of Fichte's position is projected for the first time.

The principle of Fichte's system is the pure thinking that thinks itself, the identity of subject and object, in the form Ego=Ego. [Here] one has the authentic principle of speculation boldly expressed. However, as soon as [Fichte's] speculation steps outside of the concept that it establishes of itself and evolves into a system, it abandons itself and its principle and does not come back to it again. It surrenders

\footnotetext{
${ }^{11}$ Subjectivity, for Fichte, requires self-consciousness, but self-consciousness itself always requires opposition or limitation by something other. This is the so-called Principle of Resistance spelled out in the $\$ 5$ of the 1794-95 Wissenschaftslehre, and echoed later in the psychoanalytic tradition.
} 
Reason to the intellect and passes over into the chain of finite consciousness from which it never reconstructs itself again as identity and true infinity. ... Ego=Ego is transformed into the principle 'Ego ought to be equal to Ego. (DZ 81-82, emphasis added)

We can see here all the elements of the charge of Bad Infinity; all that is missing is Hegel's trademark term. Indeed in this case Hegel has even hit upon the term for its positive correlate. Fichte's subject never attains to true infinity, and hence the Wissenschaftslehre ultimately fails to vindicate the "authentic principle of speculation" which it nonetheless “boldly expresses." In the end, Hegel's criticisms of Fichte, both early and late, can be summarized in two slogans of the Differenzschrift. For Fichte, the Absolute I does not exist but ought to exist. And second: Fichte discovered the principle of speculation but he ultimately betrayed it. It is in virtue of this bold failure that Hegel treats Fichte as the philosopher of bad infinity par excellence.

\section{$\S 3$ Fallacies in the Differenzschrift}

I turn now to undertake a critical assessment of the confrontation I have so far only reported. I should acknowledge at the outset what is probably obvious already: namely that my own sympathies in this matter lie with Fichte. But this is by no means to say that I count Fichte the winner in this debate. At this stage the matter remains genuinely undecided for me, and I am open to the possibility that the Hegelian position may contain some unanswerable criticism. I believe this is a matter worth pursuing, both because of its intrinsic interest, and because I think the issues themselves are quite deep and fundamental. Indeed in the last analysis the question at issue here concerns the sorts of goals human beings and human institutions ought to set for themselves. It is a choice, as we might put the point, between number-line-goals, unattainable and incompletable in principle, or Möbius-Strip-goals, which might satisfy our aspirations with forms of completeable totality. Given the import of these alternatives, I wish I had some elegant and eloquent manner of settling the dispute. I do not. What I offer instead resembles much rather a kind of Cat Fight between the Fichtean and Hegelian positions much more by way of spitting and scratching than sober syllogisms. I am not sure why the contest takes this form for me. In part it may be a sense for the way Fichte himself might have conducted the fight, had he chosen to join it. But for better or worse, it is the path I take in what follows; we must see then how far we can get with it.

In defending the Fichtean position, I propose to start by making three strategic concessions. Firstly, I propose in effect to concede Hegel's basic distinction. I think Hegel is right to distinguish two fundamentally different forms of infinitude; indeed I think of this distinction as marking one of Hegel's most fundamental and enduring philosophical contributions. Moreover, I think Hegel is right in claiming that the model of Bad Infinity has dominated our thinking about infinitude, and that this dominance has in fundamental ways served to blind us to structures that deserve to be described as infinite. But I want to exercise some care in making this first concession. I want to be clear that I am 
conceding the Hegelian distinction as a distinction between two forms of infinitude. It is for this reason that I have not followed the now-dominant trend of translating schlechte Unendlichkeit as Spurious Infinity. I think it would be silly and misleading to deny that, e.g., the number series is infinite. As I see it it really is infinite; the point is that it does not represent the only exemplar of infinitude, even in the mathematical domain. But of course all this leaves open the central question, viz., whether rational subjectivity should be understood as exemplifying bad or good infinitudes.

Secondly, I want to concede the main elements of Hegel's summary of the core position of the Wissenschaftslehre, including his account of Fichte as the philosopher of Bad Infinity. This marks a departure from a long-standing tradition among Fichte's sympathizers, who have complained about Hegel's systematic misrepresentation of Fichte's genuine position. I myself have on occasion joined this chorus, but I now think that it is the wrong song to sing. Indeed I am now convinced that Hegel is one of Fichte's most astute readers, and that he shows a remarkable ability to find the crucial structure and trajectory of Fichte's core commitments amid the deplorable chaos that characterizes so much of Fichte's corpus. Misrepresentations on particular points can no doubt be identified, but on the core disputed issues I think Hegel has Fichte right: he does take subject-object identity to be the fundamental principle of philosophy; he does hold that it is unattainable in principle because selfdestructive if achieved; and he does indeed seek to manage this contradiction by projecting the I into infinitude, positing the absolute self not as a fact but as a goal, not as real but as ideal, as a norm by which we are oriented and by which we must ultimately assess our endeavors. In short, I concede Hegel's Bad Infinity summary of Fichte's position. What I want to consider whether Bad Infinity is indeed so bad after all.

Finally, I propose to concede - at least for the purposes of argument here - that Fichte's arguments in the Wissenschaftslehre may not suffice to establish the main tenets of his distinctive position. At several points Fichte himself seems to concede as much, announcing in one famous formula that "the kind of philosophy one chooses depends on the kind of person one is," and elsewhere making much of the fact that his so-called "dogmatic" opponent is in principle irrefutable. ${ }^{12}$ My own concession on this point is strictly strategic. For the purpose of this discussion I propose to keep the focus squarely on Hegel's critique of Fichte, in order that we might assess its merits. Accordingly I propose to steer clear of the much more complex and substantial task of reconstructing and assessing Fichte's arguments for his Bad Infinity Idealism. ${ }^{13}$

This concludes my concessions, which I hope will serve to focus our attention on the matter at hand. First, what objections does Hegel actually offer to Fichte's distinctive idealism of infinite ideals? And second, how if at all might Fichte defuse those objections? In considering these matters I propose

\footnotetext{
${ }^{12}$ Both of these claims are found in the introductions to the abortive Neue Versuch version of the Wissenschaftslehre, as published in 1797.

${ }^{13}$ Some time ago I undertook a first attempt at this more substantial task, though I there kept strategically quiet about the specifically infinitistic character of Fichte's practical idealism. See Martin, Idealism and Objectivity: Understanding Fichte's Jena Project (Stanford University Press, 1997).
} 
to conduct my cat fight in two phases. Call the first phase: "Hegelian Fallacies." The way to get this first phase underway is to ask ourselves explicitly: What reasons does Hegel actually give in the Differenzschrift for rejecting Fichte's idealism of the Bad Infinite? To this point we have simply documented Hegel's summary of Fichte's position; but on what grounds exactly is the Fichtean position rejected? Here I propose that in the last analysis there is really not much of a Hegelian case for the Fichtean to answer. What if Fichte had simply responded to the Differenzschrift by saying in effect, "Sir, you have understood me exactly"?

There is one point in Hegel's analysis that sounds like an objection. Both early and late, Hegel alleges that Fichte betrays his own principles. According to Hegel, Fichte discovered the principle of speculative philosophy; he proposed to make subject-object identity the first principle of his system. But, Hegel alleges, Fichte failed at just this task. This sounds like an example of what would later come to be called Hegelian immanent criticism. The Wissenschaftslehre, it seems, fails to live up to its own internal standard of success.

In fact, however, this purportedly immanent argument is wholly fallacious. Nowadays we might call it a Straw Man Fallacy, or simply "begging the question". But it is more fitting to characterize it in the preferred terms of the journal Hegel himself was editing at the time. Accordingly, as a first-pass Fichtean reply to the Differenzschrift I propose the following: Hegel is guilty of merely negative criticism. In the Introduction to their Critical Journal, Schelling and Hegel themselves emphasize the impotence of merely negative criticism. It does no good to criticize one's philosophical rivals on the grounds that they have not seen fit to endorse one's own philosophical conclusions: "one bare assurance is worth just as much as another." ${ }^{14}$ But upon scrutiny we can see that this is exactly what Hegel does in his critical treatment of the Wissenschaftslehre. The crucial point concerns the proper interpretation of the idea that, as Hegel puts it, the principle of the Wissenschaftslehre is the principle of subject-object identity -- the principle of an Absolute I that overcomes its opposition to a not-I. Hegel simply assumes that this principle is to be understood, as it were, as a Möbius Strip principle - that is, as a form of infinitude that can be present as a completed and attained totality. Once this assumption is made then of course Fichte's position looks like a failure. But this is simply to impose an alien standard of assessment on Fichte's position. For although Fichte does indeed speak of such absolute or unconditioned identity as the "first principle" of philosophy, he clearly signals - from the very first section of the original version of the Wissenschaftslehre - that this identity is to be understood "not as something that exists, but as something that we ought to, and cannot achieve." ${ }^{15}$ If

\footnotetext{
${ }^{14}$ This famous remark comes from the Introduction to The Phenomenology of Spirit, §76 in Miller's translation. For the jointly authored editorial statement of Critical Journal, see Schelling and Hegel, "Ueber das Wesen der philosophischen Kritik überhaupt, und ihr Verhältniß zum gegenwärtigen Zustand der Philosophie insbesondere" Kritisches Journal der Philosophie I:1 (1802), iii-xxiv; translation by H.S. Harris in di Giovanni and Harris (trans.) Between Kant and Hegel (Albany, NY: SUNY Press, 1985), 272-291.

15 J.G. Fichte, Grundlage der gesamten Wissenschaftslehre (Jena: 1794-95), §1. See Heath and Lachs: Fichte:

The Science of Knowledge (Cambridge University Press, 1970, 1982), marginal pagination I, 101.
} 
Hegel's objections simply impose his own, deeply un-Fichtean interpretation of the principle of subject-object identity, then his attack on the Wissenschaftslehre can justly be dismissed as a case of merely negative criticism, which by the policy of the journal Hegel was editing, should not be considered philosophically decisive or even very illuminating.

$\S 4$ On Bad Infinite Ideals

But we cannot just leave it at that. Partly this is because the issues here are just too important to settle by poking holes in a 200-year-old essay. But it is also because there is a genuine question about the coherence of the position Fichte proposes. Accordingly I undertake now to extend the dispute by introducing a strategy whereby the Hegelian might bolster Hegel's own fallacious arguments. If there is to be any substance to Hegel's critique of Fichte, I suspect that its force is to be found in the charge that there is ultimately something incoherent about Fichtean Bad Infinitude. I think that this is indeed a serious concern, so I want to explore this charge and see how Fichte might respond to it. Let me start by developing the objection along three interrelated lines.

The Formula of Despair. I begin with an explicitly psychological version of the objection. We must seriously consider the psychological stability of the Fichtean subject, oriented as it is by ideals that it recognizes to be unattainable in principle and by obligations that it can never fulfill. For to set such goals for oneself is to cultivate despair. If this is true then Fichtean Bad Infinitude is itself intrinsically unstable. Suppose I set myself the goal of having a weed-free organic lawn. I dispose of all my herbicides and sit down with my weeding tools, pulling out dandelions and burr-clover. My progress is slow, but I am determined. But I soon realize that beneath each burr-clover I pull there are a thousand tiny burr-clover seeds, each waiting patiently to sprout in the carefully prepared soil I leave behind. I turn around and see my son blowing the heads off dandelions, and a flock of birds distributing seed. Before long I despair: "To hell with it; I'll have a meadow instead." The key point here is the pressing problem of retaining one's allegiance to a goal which one recognizes to be unattainable. If I really do recognize that one of my goals is unattainable, then surely the rational and proper thing is to reassess my goals. To do otherwise is an obsessional disorder. There is, in fact, a long-standing clinical literature concerned with just this phenomenon. The psychological description is "perfectionism" (considered here as a character trait), and it is standardly treated as a psychological disorder - something that requires treatment. One reason it is thought to require treatment is that it is systematically associated with a range of sometimes debilitating symptoms: negative affect, neuroticism, depression and anxiety, obsessive-compulsive disorder, low self-esteem, and what the psychiatrists politely refer to as "suicide ideation."16 In short, there seems good empirical reason to suspect that a Fichtean subject would have to be unstable as well as irrational.

\footnotetext{
${ }^{16}$ For a recent survey of this literature, see Flett and Hewitt, "Perfectionism and Maladjustment: An Overview of Theoretical, Definitional, and Treatment Issues"; in Flett and Hewitt, Perfectionism: Theory, Research, and
} 
The Formula of Impossible Intentions. So expressed the Hegelian objection is cast in psychological terms, but we might well see the psychological facts as reflective of an underlying transcendental condition. The having of intentions and the setting of aims and goals is subject to conditions and constraints, and it is far from clear that the Fichtean subject manages to satisfy them. One version of this objection can be framed with reference to mid-twentieth century analytic philosophy of action, where for some time it was the received view that noone can seriously intend to do something she believes to be impossible..$^{17}$ I can form an intention to throw a ball across the room, or across the courtyard, or over the wall, or over the house. But I simply cannot form the intention to throw the ball over the moon, or out of the solar system. I can wish to fly like a bird, I may pretend to fly like a bird, I might dream about flying like a bird, but I just cannot seriously intend to fly like a bird. (Try it.) Intention is a state of mind of a rational agent, and it is accordingly subject to rational constraints. The ideals of the Fichtean subject seem to fall pretty clearly afoul of such constraints, if the very possibility of intention precludes intending to do what one knows to be impossible.

A Kantian Formula. In the first two versions of this objection I have drawn on literatures that lie outside the ambit of German Idealism. But there is a way of bringing the matter much closer to home in terms of the Kantian principle that ought implies can. One of the fundamental commitments of Kant's approach to the theory of agency lies in the thought that intentional action is possible only in a framework governed by transcendental principles. The most basic such constraint for Kant is the socalled Hypothetical Imperative: to will the end is to will the means. If I genuinely intend to achieve some end (rather than simply wishing for it, for instance) then I must also intend to do such things as are necessary conditions on bringing the end about. Only given the governance of this principle is determinate intention intelligible at all. But Kant also famously holds that 'ought' implies 'can,' and here again we might well find a kind of transcendental condition on the possibility of forming serious intentions or positing goals. The principle that 'ought' implies 'can' has been much discussed, but the core thought is that one can only have an obligation to do something if it is in fact within one's power to do it. ${ }^{18}$ Hegel himself claims that this principle is an analytic tautology (SL 133). But now it seems that the ought-implies-can principle has a plain corollary. If 'ought' implies 'can' then 'cannot' implies 'not-ought.' More fully: let P represent "I ought to $\phi$ ", where $\phi$ is in turn the name for some

Treatment (Washington D.C.: American Psychological Association, 2002). For an opposing view, see Stoeber, J., \& Otto, K., "Positive Conceptions of Perfectionism: Approaches, Evidence, Challenges," Personality and Social Psychology Review, 10 (2006), 295-319.

${ }^{17}$ See for instance Paul Grice, "Intention and Uncertainty”, British Academy Lecture (London: Oxford University Press, 1971), and Al Mele, "Intention, Belief and Intentional Action”, American Philosophical Quarterly 26 (1986), 19-30. The received view is challenged by Kirk Ludwig, "Impossible Doings", Philosophical Studies 65:3 (1992), 257-281. 
action. Let Q represent "I can $\phi$." According to the Kantian maxim, P entails Q; $(\mathrm{P} \rightarrow \mathrm{Q})$. But then by modus tollens $(\sim Q \rightarrow \sim P)-$ i.e., if it is not the case that $\mathrm{I}$ can $\phi$ then it is not the case that I ought to. The principle that ought implies can is often treated as a truism of moral philosophy. It is thus important to recognize just how squarely Fichtean Bad Infinitude falls afoul of it. As we have seen, the Fichtean subject is defined by its conviction that there are certain fundamental goals that 'we ought to but cannot achieve.' If 'ought' implies 'can' then the Fichtean subject can aptly be dismissed as transcendentally incoherent.

Having now provided the Hegelian with some arguments, we are faced with the task of constructing a Fichtean reply. In effect the trio of arguments just proposed have all sought to establish that stable commitment to Bad Infinite Ideals is in principle impossible. One effective strategy of reply to this form of argument would be simply to demonstrate their actuality. If they are actual then they must be possible, and hence something must have gone wrong in the arguments which purported to establish otherwise. Accordingly in what follows I argue for the actuality of Bad Infinite Ideals - i.e., that real people really do act in accordance with ideals which they recognize to be unattainable in principle. This is a phase of my cat fight where Fichte can draw in some powerful allies for his cause. Consider:

Example 1: The Pauline Ideal in Christian Ethics. In the Gospels, Jesus is reported as having enjoined his disciples: "Be ye therefore perfect, even as your Father which is in heaven is perfect." (Matthew 5:48). A rich strand in Christian Ethics - particularly in the Pauline Tradition situates the Christian life specifically in the context of impossible ideals. Paul is often reported as having enjoined Christians to "Live the life of Christ" -- an injunction now reflected on American bumper stickers in the form "What would Jesus do?". The Pauline Epistles don't in fact say exactly that (Galations 2:20 enjoins the Galations to "Let Christ live through you."), but nonetheless the Pauline Ethical tradition has often interpreted this to mean that a Christian should live as Christ lived that is, faultlessly. Let's follow the tradition and call this "The Pauline Injunction". The Pauline Injunction functions, I think, as both a prototype and a schema for a common configuration of moral consciousness, one that is found in both religious and secular varieties. But it would seem that Paul is enjoining the poor Galations to live up to a standard which is strictly impossible for them to attain. For it is of course a second doctrine of Pauline Christianity that all those Galations are infected by original sin. They are not God-Men; they cannot trace their genesis to an act of immaculate conception; hence the kind of life that Christ led is strictly out of reach for them. Here, then we seem to find an prominent configuration of moral consciousness that conforms to the Fichtean pattern. Pauline Christians seem to take themselves to be governed by an overarching ideal or standard that is strictly impossible for them to satisfy: ought but cannot.

\footnotetext{
${ }^{18}$ For discussions of the principle see John Kekes, "Ought Implies Can and Two Kinds of Morality”,

Philosophical Quarterly 34 (1984), 459-467; and Stern, Robert, “Does 'Ought' Imply ‘Can'? And Did Kant Think it Does?"; Utilitas 16:1 (2004), 42-61.
} 
Example 2: Empirical Science as understood by Kant and Husserl. For a second example perhaps somewhat closer to home, I appeal to the model of empirical scientific investigation found in Kant and Husserl. Obviously this is far too big a topic to tackle here. All I want, however, is to point to a crucial feature common to the Kantian and Husserlian accounts of scientific explanatory practices. For as is well-known, both Kant and Husserl hold that scientific explanation is carried out with reference (either explicit or implicit) to the ideal of a complete explanation. Yet both also maintain that the ideal of a complete explanation is in principle out of reach of empirical scientific inquiry. In its Kantian guise, this pair of claims is found in the account of the role of the unconditioned in our explanatory practices, and in the Kantian notion of a regulative ideal. According to Kant, our rational activities are constantly oriented by our attempt to attain the unconditioned - a complete explanation, a full account of causal conditions, etc. But Kant insists at the same time that we can never attain the unconditioned by pursuing empirical science. Whatever scientific fact we arrive at will always call out for a further investigation as to why that fact is the way it is. This, I think, is closely related to a prominent theme in Husserl's philosophy of science: the idea that scientific rationality is oriented by what Husserl famously calls "infinite ideals." In scientific rationality we seek reasons that are valid universally, for anyone, with full generality, and with a kind of final authority. But in both Kant and Husserl it is explicitly held that these constitutive orienting ideals of scientific investigation are in principle unattainable. The unconditioned can never be attained, according to Kant. The pursuit of infinite ideals is itself an infinite task, according to Husserl. If they are right, empirical natural science itself presents an example - and indeed an exemplar - of a form of motivation that would be strictly impossible if the arguments we considered above were correct.

Example 3: Yorick. To round out my Fichtean allies I want finally to bring in Shakespearean infinitude. Shakespeare has Hamlet describe Yorick in terms of his infinitude: “Alas poor Yorick, I knew him Horatio, a fellow of infinite jest." Shakespeare doesn't give us much to go on in filling out this characterization. Yorick is already dead, of course, so we never get to see his jestful character at work. But it is worth thinking about what it can mean to have described him in this way. In what, exactly, does or did or indeed could Yorick's infinitude consist? I propose that we should think of it in this way. Yorick was of course a jester at court. To say that his jest was infinite presumably means that it had no limit. And in particular it meant that no matter what terrible things happened in Elsinore, Yorick could make people laugh about it. It is worth noting that in this respect Yorick would seem to be a bit like Shakespeare himself. Even in plumbing the darkest and most depressing aspects of human existence, Shakespeare always shows this capacity to elicit laughter as well. I want to suggest that here again we should recognize a configuration of motivation to counterbalance the Hegelian arguments we considered above. Yorick's jestfulness was indeed an infinite task. Terrible, depressing and horrifying things keep happening at Elsinore, so a poor jester can never rest. As soon as one joke has been completed there will be another occasion requiring one. So Yorick goes on and on and on, oriented by his distinctive ideal, his work never done. Does he despair? No. If he had then Hamlet could not have described his jest as infinite. But neither did he complete the task of jestfulness. He died, just when the task of jesting was to become the most challenging at Elsinore, his 
work never completed. Indeed even in death there seems to be a respect in which restful completion is denied him. His skull, it seems, lies unburied in the graveyard, available to serve as occasion for Hamlet's unjestful musings.

We could go on with examples like these. I suspect that in fact this kind of infinitude in human motivation is found in many avenues of human endeavor. But let's stop with this band of allies for now. Fichtean motivation is not impossible, as the Hegelian arguments allege. It is actual. We find in it Pauline ethical consciousness, in Kantian/Husserlian scientific rationality, and in Shakespearean jestfulness. In all these cases we find examples of the setting of aims, norms and ideals - call them Bad Infinite Ideals - which establish a goal for actual human endeavors, and a standard of criticism by which such endeavors are to be assessed, even in the face of the settled conviction that attaining those ideals is impossible.

Unfortunately, however, this will not be enough to settle the matter. It should be clear already that the Hegelian will not be content with these examples. We can expect the Hegelian retort to take the form of a dilemma. We have proposed a range of cases which purportedly illustrate infinite ideals at work in human motivation. In each case, however, the Hegelian will challenge our characterization of the case. In particular, it will be held that either we have misdescribed the actual motivations and obligations at work in these cases, or else that the goals in question are in principle attainable. We can see the basic texture of this dilemma by considering some of the disputes that have unfolded within the Pauline tradition to which I have referred. I have characterized the Pauline Injunction as an infinite ideal - as a call to live up to a standard that will always and in principle remain beyond our reach. But is this in fact the right way to conceive it? The Pauline tradition divides over just this question. Would it not be perverse for God to call us to do something that is impossible for us? Would that not make God into an arbitrary tyrant? In order to avoid this conclusion, a third Pauline doctrine is often introduced: the doctrine of kenosis. Kenosis means emptying, and refers specifically to Christ's reported emptying of his divine nature in order to live a human life:

Philippians 2:7: [he] emptied [ekenosen] himself, taking the form of a servant, being made in the likeness of men, and in habit found as man.

How does this Christological doctrine bear on the issues about infinite ideals? The relevance is indirect but significant. For if Christ indeed emptied himself of his divine nature, if he lived the life of man, then the flawless life he led is in fact recognizable as a human life, and hence is not in principle unattainable for beings like us. If we accept this Christological doctrine, in short, we purge the Pauline ideal of its Bad Infinity. The Pauline goal remains a stringent and demanding standard to be sure, but it is not in principle unattainable for Galatians and other finite human souls.

From the Hegelian perspective, this sort of dynamic can be expected to play out wherever purportedly Bad Infinite Ideals are identified. If they are really to play a role in our motivational economy they must be attainable. The athlete may say that he wants to put in the perfect performance, but what he means is that he wants to be better than all the competitors. The human rights worker might be described as working to bring an end to human rights violations, but in fact she must be striving to do all she can to alleviate and prevent them. Here it may be worth recalling that in during 
the first few days of the military operations initiated in response to the events of 9/11, the Bush White House formally dubbed the campaign “Operation Infinite Justice.” But this characterization of the endeavor was quickly reconsidered, reportedly in response to religious critics who insisted that infinite justice was not given to men, being rather reserved as the prerogative of divine retribution. This accords with the anti-Fichtean conviction we have been exploring here: that human goals must may be demanding and stringent but must always remain attainable for limited beings like us.

At this point we seem to have reached a stalemate. The Fichtean insists that certain fundamental ideals are bad-infinite in structure: in principle unattainable and uncompleteable, giving rise to an endlessly iterated series of finite endeavors. The Hegelian denounces such ideals, claiming that this form of infinitude is schlecht - psychologically debilitating and transcendentally incoherent. The Fichtean responds by citing what seems to be a long and rich tradition in human endeavor of just this sort of Bad Infinite struggle, which in many cases seems to be neither debilitating nor impossible. But each of these examples is challenged, with the claim that the agents involved have been mischaracterized, perhaps even by themselves. If the quarrel is to continue along these lines then it seems that it must degenerate into a series of undecidable hermeneutic skirmishes between rival interpretations of these historical configurations of human motivation, with each side approaching the hermeneutic task with an interpretative framework that will ensure their own success.

It was in fact one of Fichte's metaphilosophical convictions that the most important philosophical disputes end in just this sort of standoff. The debate between freedom and determinism, the debate for and against idealism, the debate between the moral egoist and the proponent of the moral law ... - all these debates, according to Fichte, are ultimately undecidable by rational argument alone. In such circumstances Fichte himself characteristically and notoriously resorted to ad hominem argument, so it is perhaps not unfitting to conclude with such arguments here as well. We face a choice in these matters, a choice that in the last analysis concerns the sort of ideals that we should set for ourselves, the standards of behaviour we should aim at, and the norms by which we should measure our success. For Hegel, those goals may be infinite but they must be completeable -- infinite totalities within reach of finite human beings and their institutions. Like bank managers and business consultants and accountants, the Hegelian counsels us to set realistic targets within reach of our powers, ambitions that we can then hope to satisfy. The question is whether we should follow this sensible counsel, or stand instead with Kant and Husserl and Fichte and Shakespeare and Yorick and Pauline Christians, who together share the conviction that what is distinctive about human existence and human dignity is in part the fact that we find ourselves situated with regard to demands that we can never finally fulfill, but which continue to exert their infinite authority over us. As Fichte puts it at the close of one of his notorious Sunday morning lectures:

It is part of the concept of man that his ultimate goal be unattainable and that his path thereto be infinitely long. Thus it is not man's vocation to reach this goal. But he can and he should draw nearer to it, and his true vocation qua man, that is, insofar as 
he is a rational but finite, a sensuous but free being, lies in endless approximation toward this goal. ${ }^{19} 20$

Wayne M. Martin

Department of Philosophy

University of Essex

Wivenhoe Park, Essex CO4 3SQ

wmartin@essex.ac.uk

${ }^{19}$ J.G. Fichte, “Some Lectures Concerning the Scholar's Vocation”; translation by Breazeale in Fichte: Early Philosophical Writings (Ithaca, New York: Cornell University Press, 1988), 152.

${ }^{20}$ Earlier versions of this paper were delivered at the 2006 conference of the Hegel Society of Great Britain (Oxford) and at the 2007 meeting of the Society for Existential Phenomenology (Berkeley). Research assistance was provided by Garrett Miller. In working on this paper I have benefited from helpful feedback from a number of friends, students and colleagues; among them I would like to thank in particular Joseph Schear, Stephen Houlgate, Robert Stern and James Clarke. Support for the research presented in this paper was provided by the University of Essex. 